\title{
To Study the Effectiveness of the Training Program on Safe Administration of Drugs to Reduce the Medication Error
}

\author{
Srinithya Raghavan', Urmila Bhardwaj', Seema Rani ${ }^{3}$ \\ ${ }^{1}$ Nursing Officer, AlIMS, Delhi, India. \\ ${ }^{2}$ Professor, ${ }^{3}$ Associate Professor, Rufaida College of Nursing, Jamia Hamdard, Delhi, India. \\ DOI: https://doi.org/10.24321/2348.2133.202003
}

\section{I $\quad \mathbf{N} \quad \mathbf{F} \quad \mathbf{O}$}

\author{
Corresponding Author: \\ Seema Rani, Rufaida College of Nursing, Jamia \\ Hamdard, Delhi, India. \\ E-mail Id: \\ seema9rani@yahoo.co.in \\ Orcid Id: \\ https://orcid.org/0000-0002-3133-448X \\ How to cite this article: \\ Raghavan S, Bhardwaj U, Rani S. To Study \\ the Effectiveness of the Training Program on \\ Safe Administration of Drugs to Reduce the \\ Medication Error. Ind J Holist Nurs 2020; 11(3): \\ 12-19.
}

Date of Submission: 2020-12-07

Date of Acceptance: 2021-02-26

\section{$\begin{array}{llllllll}\mathbf{A} & \mathbf{B} & \mathbf{S} & \mathbf{T} & \mathbf{R} & \mathbf{A} & \mathbf{C} & \mathbf{T}\end{array}$}

Introduction: Medication process is a complex process and errors are possible at several aspects of medication process. The present study was conducted in Neonatal Intensive Care Unit (NICU) of selected hospital, Delhi, with the objectives of investigating the incidence of medication errors in the NICU, to explore the types of medication errors occurring frequently, to develop and evaluate the training program on safe administration of pediatric drugs in terms of knowledge and skills for the nurses working in the neonatal unit.

Methodology: Research approach selected for the study was quantitative approach with pre-experimental one group pre-test, post-test design. 50 prescriptions and 138 drugs were selected for investigating the medication errors and total enumeration sampling technique was used for selecting the staff nurses for evaluating the knowledge and practice of 30 staff nurses. Tools developed and used for data collection were structured knowledge questionnaire and observation check list to assess the knowledge and practice of staff nurses on safe administration of pediatric drugs respectively.

Result: Medication errors were present in 127 (92.02\%) drugs prescribed by the pediatrician. Medication error rate was highest during drug administration process that is 117 (94.90\%) followed by the documentation error of 110 (79.7\%) whereas transcription errors accounted for $69(50 \%)$ in overall process of the medication. The prescription errors were noted in $56(40.50 \%)$ of drug prescriptions. The mean post- test knowledge and practice scores of the staff nurses on safe administration of drugs were statistically higher at 0.05 level of significance than the corresponding mean pre-test knowledge and practice scores.

Conclusion: The training program on safe administration of pediatric drugs was found to be effective in improving knowledge and practice of staff nurses.

Keywords: Medication Errors, Administration of Medication, Neonatal Intensive Care Unit 


\section{Background}

Medication errors are integral part of medical errors. Medication errors, defined as "any preventable event that may cause or lead to inappropriate medication use or patient harm while the medication is in the control of the health care professional, patient, or consumer's, are costly from human, economic, and societal perspectives." Medication errors affect $3 \%$ to $5 \%$ of hospitalized patients (Bond, Raehl, \& Franke). ${ }^{1}$

Medication errors are probably one of the most common types of medical errors as medication is the most common health care intervention (Ghaleb MA). ${ }^{2}$ of the medical errors, medication errors were reported to cause significant problems for physicians and patients and may result in serious patient morbidity and mortality, increased health-care costs, prolonged hospital stay, unnecessary diagnostic tests, and treatments and, in some cases, loss of confidence in the health care system (Lesar TS). ${ }^{3}$ Medication Error is defined as the preventable, inappropriate use of medications that may occur at any step of the medication process, namely; prescription, transcription, dispensing, administration, and drug effect monitoring (Hughes RG). ${ }^{4}$

A study documented three fold higher rate of potentially harmful medication errors in pediatric patients in the unit and according to a report by (Kaushal) $)^{5}$ the NICU has the highest number of preventable iatrogenic medication errors, with 3 of 5 pediatric adverse drug events occurring in neonates.

Children are at a greater risk than adults for medication errors because they have an immature physiological detoxification mechanism as well as developmental limitations that affect their ability to self-administer medications, and to communicate about side effects. Besides these determining, pediatric dosages is complicated by the fact that the dose needs to be individualized based on the patients' age, weight/ body surface area, and clinical condition. This leads to increased opportunities for dosing errors (Prot S). ${ }^{6}$

Basic training of nurses in pharmacology, management (rules, storage, making and administration of drugs to patients) and drug dose estimation is provided by colleges and on-the-job training under senior nurses working as tutors. The knowledge of nurses in medication is mostly undiscoverable; however, insufficient knowledge in pharmacology and drug management have been reported in some studies.

A meta-analysis study identified the relative percentages of pediatric error types as: prescribing 3-37\%, dispensing 5-58\%, administering $72-75 \%$ and documenting $17-21 \%$ (Miller MR)7. Pediatric medication errors were reported to be caused by lack of knowledge/ training, failure to follow procedures for medication administration, communication errors, calculation mistakes, improper/ failure in patient monitoring, improper use of infusion pumps and documentation (Katie Thomas). ${ }^{8}$

Nurses accountable for ensuring that they keep their knowledge and skills up-to-date throughout their working lives to ensure they deliver lawful, safe and effective practice without direct supervision. Despite increased vulnerability, pediatric medication error has received relatively little scrutiny and even less has been done to assess their preventability. So, the present study aimed to study to assess the incidence of medication error and the effectiveness of the training program on safe administration of pediatric drugs in terms of knowledge and skills for nurses working in pediatric unit of a selected hospital of Delhi.

\section{Methodology}

To accomplish the objectives of the study, quantitative approach with pre-experimental one group pre-test and post-test design was adopted. The study was conducted in the neonatal unit of a government hospital in Delhi. Sample comprised of 30 staff nurses selected by total enumeration sampling technique after getting their consent. Tools used for data collection were; knowledge questionnaire to assess the knowledge of staff nurses regarding the safe administration of pediatric drugs, an observation checklist to assess the incidence of medication error and practice of staff nurses regarding safe administration of pediatric drugs. Training program on safe administration of pediatric drugs was prepared. The structured knowledge questionnaire comprised of two sections; section I comprised of items seeking personal information of subjects like age, sex, professional experience, working experience in pediatric unit, any special training course attended on safe administration of pediatric drugs. Section II comprised of four parts including multiple choice questions, fill in the blanks, matching the columns and True/ False statements related to the common abbreviations, mathematical calculations of the pediatric drugs, safe administration of pediatric drugs. Each item had single correct option in section II. For the correct response, 'one' and for a wrong response, 'zero' score were given. The range of scores was $0-45$. According to the percentage of scores attained, the following categories were developed:

- Above Average: a score of 34 and above $(70 \%$ and Above)

- Average: a score of $>27$ and $<34$ ( $>60 \%$ and $<70 \%)$

- Below Average: a score of $<27(<60 \%)$

The structured observation checklist was developed to assess the incidence of medication error and the practice of staff nurses on safe administration of pediatric drugs. The section III comprised of two parts; part I about demographic profile of the babies; whose prescriptions were under study for evaluating the incidence of medication error and part 
II consisted of 18 activities to be observed which were designed to observe staff nurses' practice regarding safe administration of pediatric drugs. All the items in section III, part II were structured, a score of two (2) was assigned for each correctly performed activity, a score of one (1) assigned for each unsatisfactorily performed activities and a score of zero $(0)$ assigned for activity not performed or any failure to execute the act. The scores ranged from $0-36$. According to the percentage of scores attained, the following categories were developed:

- Good Practice (>75\%)- a score of 27 and above

- Average Practice (61-75\%)- a score of 22-26

- Poor practice( Below 61\%)- a score of less than 22

The training program consisted of pharmacological concepts, measurements and calculations of the commonly used drugs in the paediatric units, nurses' responsibilities in medication administration including ethical and legal aspects, safe handling of pediatric drugs before and during the preparation of the drugs, administration of oral and intravenous medication, importance of documentations and bio medical waste management. Average time taken by the researcher for one complete observation was 30 minutes. Tools and the training program were validated by seven experts from the fields of medicine and nursing practice and education. Reliability of structured knowledge questionnaire was 0.78 using KR 20 formula. The reliability of the observation checklist was 95 established through Inter Observer reliability. After obtaining formal approval and permission from a selected hospital in Delhi, Pre-Test knowledge questionnaire was administered to staff nurses, later observed for their practice with the help of a structured observation checklist. A verbal introduction was given to the staff nurses regarding the training program on safe administration of pediatric drugs. Then the training program was administered to the staff individually by the researcher. The researcher also demonstrated the procedure. Post-Test was conducted on day. ${ }^{14}$

\section{Result}

\section{Section: I a) Categories of Drugs Evaluated for Calculating the Incidence of Medication Error}

Total 138 drugs prescribed were evaluated for the incidence of medication error and these drugs fell into 7 categories. Majority of the drugs prescribed were antibiotics 93 (67.4\%), followed by Electrolyte/ Nutritional Supplements 27 (19.6\%). Beta- antagonist/ Bronchodilators were only 7 (5.1\%), Hypnotic/Sedative/ Opioid accounted for 5 (3.6\%) and Xanthine Derivative, Barbiturate/ Anticonvulsant and Inotropes 2 (1.4\%) each.

\section{Section- I b): Findings related to the Incidence of Medication Error}

This section represents the incidence of medication errors during medication Process. All errors are categorized according to the process of medication (Prescription, Transcription, Administration and Documentation). Errors in each aspect of the process are further represented with their types.

Table I.Frequency and Percentage distribution of incidence of medication error

$n 2^{*}=138$

\begin{tabular}{|c|c|c|}
\hline $\begin{array}{c}\text { Incidence of medication } \\
\text { error }\end{array}$ & $\begin{array}{c}\text { Frequency } \\
\text { (f) }\end{array}$ & $\begin{array}{c}\text { Percentage } \\
\text { (\%) }\end{array}$ \\
\hline Medication Error & 127 & 92.03 \\
\hline No Medication Error & 11 & 7.08 \\
\hline \multicolumn{2}{|c|}{}
\end{tabular}

As evident from Table 1, out of 138 drugs evaluated, medication errors were present in 127 (92.03\%) drugs prescribed by the pediatrician. It is evident that more than $90 \%$ of drugs evaluated were found to have error from prescription to documentation and only 11 (7.08\%) drugs had no error.

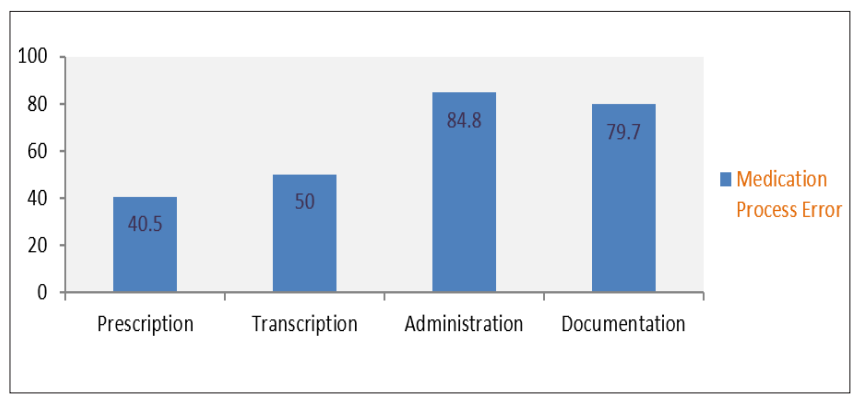

Figure I.Bar diagram showing the percentage wise distribution of Medication Process Errors

Table 2.Frequency and percentage distribution of general prescription error

\begin{tabular}{|c|c|c|}
\hline General prescription errors & $\begin{array}{c}\text { Frequency } \\
\text { (f) }\end{array}$ & $\begin{array}{c}\text { Percentage } \\
\text { (\%) }\end{array}$ \\
\hline $\begin{array}{c}\text { Legibility of the } \\
\text { prescription }\end{array}$ & 4 & 8 \\
\hline $\begin{array}{c}\text { Error related to omission of } \\
\text { weight }\end{array}$ & 2 & 4 \\
\hline $\begin{array}{c}\text { Use of non-standard } \\
\text { abbreviation }\end{array}$ & 2 & 4 \\
\hline
\end{tabular}

*Prescriptions under the study.

Common prescription errors included Legibility, omission of weight and use of non- standard abbreviations as evident from Table 2. The most common non-standard abbreviation used is for drops as 60. All prescriptions evaluated during the study period had signature of the pediatrician and no contraindicated drugs were prescribed by the pediatrician. 
Table 3.Frequency and percentage distribution of types of drug Specific Prescription Errors

n2 * =138

\begin{tabular}{|c|c|c|}
\hline $\begin{array}{c}\text { Types of drug specific } \\
\text { prescription errors }\end{array}$ & $\begin{array}{c}\text { Frequency } \\
\text { (f) }\end{array}$ & $\begin{array}{c}\text { Percentage } \\
\text { (\%) }\end{array}$ \\
\hline $\begin{array}{c}\text { No drug specific prescription } \\
\text { error }\end{array}$ & 82 & 59.4 \\
\hline $\begin{array}{c}\text { Omission of Route of the } \\
\text { parenteral drugs }\end{array}$ & 50 & 36.2 \\
\hline Error in Dosing schedule & 47 & 34 \\
\hline $\begin{array}{c}\text { Errors related to duration } \\
\text { of administering parenteral } \\
\text { drugs }\end{array}$ & 26 & 18.8 \\
\hline $\begin{array}{c}\text { Dose Errors (Greater/ } \\
\text { less than the 10\% of } \\
\text { Recommended dosing } \\
\text { range/ 24hours }\end{array}$ & 10 & 7.2 \\
\hline
\end{tabular}

*Number of drugs under the study.

As shown in in table 3, out of 138 (100\%) drugs, 82 (59.5\%) had no error in drug specific prescription and $56(40.5 \%)$ had error. Some of the drug specific prescription even had more than one error.

Table 4.Frequency and Percentage distribution of Types of Transcription Errors

$\mathrm{n} 2 *=138$

\begin{tabular}{|c|c|c|}
\hline Transcription Errors & $\begin{array}{c}\text { Frequency } \\
\text { (f) }\end{array}$ & $\begin{array}{c}\text { Percentage } \\
\text { (\%) }\end{array}$ \\
\hline No error in Transcription & 69 & 50 \\
\hline $\begin{array}{c}\text { Wrong/ Omission of } \\
\text { duration of administering } \\
\text { IV drugs }\end{array}$ & 55 & 39.8 \\
\hline $\begin{array}{c}\text { Wrong/ Omission of drug } \\
\text { Frequency }\end{array}$ & 55 & 39.8 \\
\hline $\begin{array}{c}\text { Wrong/ Omission of Drug } \\
\text { Route }\end{array}$ & 36 & 26 \\
\hline $\begin{array}{c}\text { Wrong/ Omission of Drug } \\
\text { Form }\end{array}$ & 36 & 26 \\
\hline $\begin{array}{c}\text { Wrong/ Omission of Drug } \\
\text { Dose }\end{array}$ & 13 & 1.4 \\
\hline $\begin{array}{c}\text { Wrong/ Omission of Drug } \\
\text { Name }\end{array}$ & 2 & 9.4 \\
\hline
\end{tabular}

* Number of drugs under the study.

The types of transcription errors as shown in Table 4, illustrate that maximum of 55 (39.8\%) of transcription errors were attributed to wrong/ omission of duration of administering IV drugs and wrong/ omission of drug frequency.
Table 5.Frequency and Percentage distribution of Drug administration errors

$*_{\mathrm{n} 2=138}$

\begin{tabular}{|c|c|c|}
\hline Drug Administration Error & $\begin{array}{c}\text { Frequency } \\
\text { (f) }\end{array}$ & $\begin{array}{c}\text { Percentage } \\
\text { (\%) }\end{array}$ \\
\hline No Administration Error & 7 & 5.07 \\
\hline $\begin{array}{c}\text { Error before Preparation of } \\
\text { the Drug }\end{array}$ & 42 & 30.4 \\
\hline $\begin{array}{c}\text { Error during the Preparation } \\
\text { of Drug }\end{array}$ & 131 & 94.9 \\
\hline $\begin{array}{c}\text { Error during the } \\
\text { Administration of Drug }\end{array}$ & 129 & 93.4 \\
\hline
\end{tabular}

*Total number of drugs under study.

Drug administration error was further observed in three processes as before preparation of the drug, during the preparation of drugs and during the administration of the drugs as depicted in Table 5.

Errors before preparation of the drug were discoloration of the antibiotics (Appearance of the Drug) 39 (28.2\%), followed by the storage of the drugs prepared 27 (19.5\%). Error was also found in the usage of non-prescribed drug (administered after discontinuation) which accounted for 2 (1.4\%). There was no error found in administering expired drug and in the drug formulation.

Errors during the preparation of the drug accounted for 131 $(95 \%)$. Maximum error occurred not practicing the infection control measures 127 (92\%), including not doing hand washing and not using sterile gloves for the preparation of IV drugs. Another common error 82 (59.4\%) found during the preparation of the drug was use of Diluents Volume for further diluting the IV antibiotics before administration which was mainly diluting the drugs in less amount of diluents. 74 (53.6\%) drugs had wrong calculation of dose and $4(3 \%)$ drug error found in the incorrect choice of diluents which were used for reconstitution of the IV drug.

The incidence of error during administration of the drug accounted in 129 (93.4\%) drugs. Not labeling the loaded syringes for injection when they prepare for more than one injections that accounted in 122 (88.4\%) drugs, and next common error 120 (86.9\%) was not practicing the infection control measures like hand washing, wearing sterile gloves for administering IV drugs and not practicing hand washing or use of hand scrub between patients while administering the drug. 109 (78.9\%) errors accounted against time duration of administering IV drugs. Antibiotics which are supposed to be administered over 30 minutes were administered very fast. Time error was found in 48 $(34.7 \%)$ as the drug were not administered at right time

As depicted in table 6, time error in drug documentation was the most frequent documentation error i.e. in 100 ( 
$72.4 \%)$, followed by incomplete documentation that accounted in $80(57.9 \%)$ drugs, other discrepancies like (wrong form/ dose/ route/ name of the drug/ diluents) were 25 (18.1\%), Documentation of un administered drugs and No documentation accounted in 10 (7.2\%) drugs each.

Table 6.Frequency and Percentage distribution of Types of Documentation Errors

$\mathrm{n} 2 *=138$

\begin{tabular}{|c|c|c|}
\hline Documentation errors & $\begin{array}{c}\text { Frequency } \\
\text { (f) }\end{array}$ & $\begin{array}{c}\text { Percentage } \\
\text { (\%) }\end{array}$ \\
\hline No error in documentation & 28 & 20.2 \\
\hline Wrong Time & 100 & 72.4 \\
\hline Incomplete Documentation & 80 & 57.9 \\
\hline $\begin{array}{c}\text { Other Discrepancies } \\
\text { (Wrong form/ dose/ route/ } \\
\text { name of the drug/ diluents) }\end{array}$ & 25 & 18.1 \\
\hline $\begin{array}{c}\text { No Documentation } \\
\text { Documentation of un } \\
\text { administered drugs }\end{array}$ & 10 & 7.2 \\
\hline * Number drugs under stud\% & & \\
\hline
\end{tabular}

* Number of drugs under study.

Section II a): Findings Related to Sample Characteristics of the Subjects

Table 7.Sample Characteristics of Staff Nurses under Study

\begin{tabular}{|c|c|c|c|}
\hline S. No. & $\begin{array}{c}\text { Sample } \\
\text { Characteristics }\end{array}$ & $\begin{array}{l}\text { Frequency } \\
\text { (f) }\end{array}$ & $\begin{array}{c}\text { Percentage } \\
(\%)\end{array}$ \\
\hline 1. & \multicolumn{3}{|c|}{ Age in Years } \\
\hline & $20-26$ & 6 & 20 \\
\hline & $27-32$ & 12 & 40 \\
\hline & $33-38$ & 9 & 30 \\
\hline & $>38$ & 3 & 10 \\
\hline \multirow[t]{2}{*}{2.} & \multicolumn{3}{|c|}{ Sex } \\
\hline & Female & 30 & 100 \\
\hline \multirow[t]{4}{*}{3.} & \multicolumn{3}{|c|}{ Professional Qualification } \\
\hline & DGNM & 24 & 80 \\
\hline & B.Sc. Nursing & 5 & 16.7 \\
\hline & M.Sc Nursing & 1 & 3.3 \\
\hline \multirow[t]{5}{*}{4.} & \multicolumn{3}{|c|}{ Total Years of Experience as a Staff Nurse } \\
\hline & 1-5 Years & 9 & 30 \\
\hline & $6-10$ years & 8 & 26.6 \\
\hline & $11-15$ years & 6 & 20 \\
\hline & $>15$ years & 7 & 23.3 \\
\hline \multirow[t]{2}{*}{5.} & \multicolumn{3}{|c|}{ Years of Experience in the pediatric Unit } \\
\hline & 1-5 Years & 16 & 53.3 \\
\hline
\end{tabular}

\begin{tabular}{|c|c|c|c|}
\hline & $6-10$ years & 5 & 16.6 \\
\hline & $11-15$ years & 4 & 13.3 \\
\hline & $>15$ years & 5 & 16.6 \\
\hline 6. & \multicolumn{3}{|c|}{$\begin{array}{l}\text { Attended any In-Service Program on Safe } \\
\text { administration of Pediatric medication }\end{array}$} \\
\hline & No & 30 & 100 \\
\hline
\end{tabular}

Table 7, gives the details of the staff nurses under the study in respect to their age, qualification, professional experience and experience in pediatric unit.

\section{Section II b): Findings Related to Knowledge of Staff Nurses regarding the safe Administration of Pediatric Medication}

II b (i) Pre- test and Post Test Knowledge scores of the staff Nurses posted in the Neonatal Unit.

Table 8.Range, Mean, Median and Standard Deviation of pretest and post- test knowledge score of Staff Nurses working in Neonatal Unit

\begin{tabular}{|c|c|c|c|c|c|c|c|}
\hline 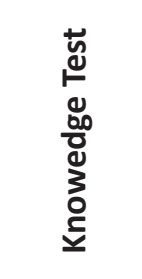 & 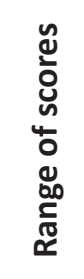 & 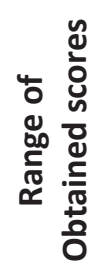 & 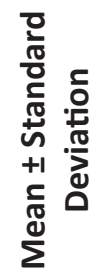 & $\sum_{\text {岃 }}$ & ด & $\begin{array}{l}\text { D } \\
\frac{c}{\mathbb{O}} \\
\stackrel{\mathbb{d}}{\Sigma}\end{array}$ & $\frac{\frac{0}{3}}{\frac{\pi}{3}}$ \\
\hline Pre-test & \multirow{2}{*}{$0-45$} & $19-38$ & $\begin{array}{l}26.6 \pm \\
5.757\end{array}$ & \multirow{2}{*}{$\begin{array}{l}1.1 \\
06\end{array}$} & \multirow{2}{*}{$\begin{array}{l}6 . \\
05\end{array}$} & \multirow{2}{*}{$\begin{array}{c}13 \\
.5\end{array}$} & \multirow{2}{*}{$\begin{array}{c}12 . \\
210^{*}\end{array}$} \\
\hline Post-test & & $34-44$ & $\begin{array}{l}40.1 \pm \\
2.440\end{array}$ & & & & \\
\hline
\end{tabular}

Table 9.Pre observation and Post observation Practice score of study subjects working in the Neonatal Unit

\begin{tabular}{|c|c|c|c|c|c|c|c|}
\hline 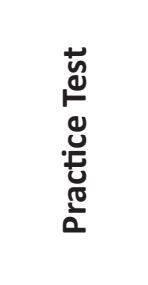 & 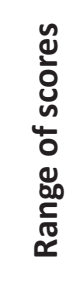 & 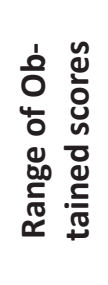 & 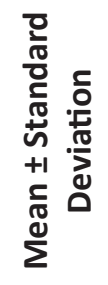 & $\sum_{\text {㞻 }}$ & ค & $\begin{array}{l}0 \\
\frac{1}{\pi} \\
\stackrel{0}{\mathscr{N}} \\
\sum\end{array}$ & $\begin{array}{l}\frac{0}{2} \\
\frac{10}{70} \\
\pm\end{array}$ \\
\hline $\begin{array}{l}\text { Pre Ob- } \\
\text { servation }\end{array}$ & \multirow{2}{*}{$0-36$} & $17-24$ & $\begin{array}{c}21.4 \pm \\
1.83 \\
\end{array}$ & \multirow{2}{*}{$\begin{array}{l}0.3 \\
06\end{array}$} & \multirow{2}{*}{$\begin{array}{l}1.6 \\
75\end{array}$} & \multirow{2}{*}{$\begin{array}{l}2 . \\
56\end{array}$} & \multirow{2}{*}{$\begin{array}{l}8.3 \\
93^{*}\end{array}$} \\
\hline $\begin{array}{l}\text { Post Ob- } \\
\text { servation }\end{array}$ & & $18-28$ & $\begin{array}{l}24 \pm \\
2.14\end{array}$ & & & & \\
\hline
\end{tabular}

$\mathrm{t}^{\prime}(29)=2.04, \mathrm{p}<0.05$ at 0.05 level of significance.

Table 8 , shows pre and post-test knowledge scores of staff nurses with respect to the medication process. The difference is statistically significant at 0.05 level. 
Section II b (ii): Findings Related to the Evaluation of the Effectiveness of the Training Programme on Safe Administration of Pediatric drugs in terms of Practice of the Staff Nurses working in the Neonatal Unit

Table 9, shows pre and post- test practice scores of staff nurses with respect to the medication process. The difference is statistically significant at 0.05 level.

\section{Discussion}

Out of 50 prescriptions, 138 drugs were evaluated for incidence of medication error. In this errors were present in $127(92.02 \%)$ drugs prescribed by the pediatrician. It can be evaluated that more than $90 \%$ of drugs had errors and only 11 $(7.08 \%)$ drugs had no error in the medication Process. These results are in line with the study by Marino BL, Reinhardt K9 which revealed that in pediatrics error has been reported to be as high as 1 in 6.4 orders. A 1995-1999 study by the US Pharmacopeia (USP) Medication Errors Reporting Program demonstrated a significantly increased rate of medication error resulting in harm or death in pediatric patients (31\%), compared with adults (13\%). In pediatrics, intravenous fluids have been recognized as the most commonly cited product causing medication errors reported to the USP. In pediatric population, the most commonly reported errors include the following: ill-suited medication; erroneous dosage or frequency of administration of medication; incorrect way of administration; failure to identify drug-drug reactions; dearth of monitoring for negative impact; "missed/ late dose errors" with delayed drug administration; and communication gap between the physician, other members of the health care team, the parent or caregiver, and the patient. For pediatrics, incorrect dosing is the most commonly reported error, including computation errors of dosage and dosing interval. ${ }^{3,5}$ The current study findings are in full or partial agreement with the results of all above quoted studies.

Prescribing is the most error prone step in the medication process because the information needs to be complete, correct, non-Ambiguous and legible. The present study identified $40.5 \%$ of prescription error which is similar with the findings of a meta-analysis (3-37\%) by Miller MR (2005)7 and another study by Aneja S10 where the findings were (37.7\%) but in partial agreement with findings of several studies i.e. 79\% Kaushal R5, 69.5\% Lesar TS3, 12.6\% Portnoy $\mathrm{J} 11$. The contrasting findings between present and previous studies might be due to variable setting of data collection and different criteria set for evaluating prescription errors.

The present study found the incidence of prescription errors as errors related to duration of administering parenteral drugs $82.7 \%$, Omission of Route of the parenteral drugs $57.4 \%$, Dose errors 56.3\%, Error in Dosing schedule 54\%. Despite variable error rates, the study findings of errors approximated the findings of previous studies: $45.5 \%$ Parihar M12, 34\% Kaushal R5. No error was related to drug-drug incompatibility, whereas in a previous study by Kopp BJ13 drug-drug incompatibilities accounted for $10 \%$ of medication errors.

Types of transcription errors related to wrong/omission of duration of administering IV drugs 39.8\%, Wrong/ Omission of drug Frequency $39.8 \%$, Wrong/Omission of Drug Route and drug form 26\%, Wrong/Omission of Drug Dose $9.4 \%$ respectively. Overall transcription errors rate found in the present study is not much supported by the findings of the study by Lisby M14 who found 4\% of drug administration, Vazin A15 3.3\% transcription errors. But the current study found $50 \%$ of transcription error which indicate that nurses are less cognitive while copying the prescriptions to treatment book.

Drug administration errors rate was found to be $95 \%$ of total medication errors, although there was no potential error relating to wrong patient, wrong drug and wrong route. High rates of drug administration errors found in present study were supported by the findings of many previous studies i.e. 72\%-75\% Miller MR7, 68.9\% Protony J 11, 48\% Rinke ML 16 , and $41 \%$ Lisby M 14 . The possible reason for the administrative error could be low nurse patient ratio (1:6-8), thereby increasing workload on individual staff.

Types of drug administration errors varied in previous studies, however the highest rate of $95 \%$ error accounted in poor practice of infection control practices. The error accounted before preparation of drugs were $30.4 \%$ which was also seen in a study by Fahimi F 17 where the preparation error was $33.6 \%$ which was more than what we find in this study. $66.4 \%$ accounted in the administration process.

Dose error in the present study was $53.6 \%$ of administration errors, whereas in previous studies, dose errors were the one of the major causes for administration errors: $31 \%$ Tissot E 18, 46.5\% Portnoy J 11, 41\%, and 22.9\% Rinke ML 16. The possible reason for the comparatively high rate of dose error may be inability of the staff nurses in calculating the very low dose of pediatric drugs. The calculation skills of staff nurses is poor in majority of the drug administration observations which was improved after attending the training program on safe administration of pediatric drugs

Documentation errors in the present study accounted for $79.5 \%$ of medication errors and were related to documentation of wrong time $72.4 \%$, incomplete documentation $57.9 \%$, documentation of un- administered drugs and no documentation $7.2 \%$. The result of the present study found that the drug administration and documentation error were significantly higher and this findings were supported by a previous study reporting 
maximum drug administration errors between $6 \mathrm{pm}$ to 10 pm Van den Bemt PM(2002)19. The possibility of high errors during evening shifts might be associated with the fact that in the evening shift, there is very less nurse patient ratio.

The Findings of the present study also revealed that the staff nurses had low level of knowledge regarding safe administration of pediatric drugs initially, whereas after administration of training program there was significant gain in the knowledge and practice. Similar study was conducted by Sullivan MM, O'Brien CR 20 to determine the effectiveness of an online module for reducing insulin administration errors by nurses caring for hospitalized pediatric patients. The pre- intervention insulin error rate was $14.8 \%$, reduced to $1.7 \%(P<0.001)$ post- intervention. The study concluded that an interactive online educational module can be an effective strategy for reducing pediatric nurses' insulin administration errors.

Another study by Simpson JH 21 where he developed combined risk management/ clinical pharmacist led education program to reduce the medication errors within NICU. Each new member of pharmacy, nursing, or medical staff was also required to successfully complete a series of dose calculations. In addition, a risk management approach was used to make several changes in practice during the study period. Interventions to reduce errors, particularly within the context of a risk management program, were found to be effective.

Despite, high incidence of medication error rates, none of the neonates developed severe injury to drugs during data collection period. The reduction of the medication error is not the sole responsibility of any single professional group; therefore, collaboration with other health professionals is central to establish processes, policies, strategies and systems that will reduce the occurrence of medication errors.

\section{Conclusion}

Incidence of medication error rate was found to be high in the neonatal intensive care unit of selected hospital, and occurred across the entire process of medication administration starting from prescription to documentation. High incidence of error occurs in administration and documentation process, which can be an intervening issue, since medication errors were greatly associated with these two factors. Nurses play a significant role in medication administration especially in the neonatal intensive care units, because nurses are the ones who predominantly administer medications to neonates. Nurses have a responsibility to ensure that children receive the right medication at the right time, and to monitor for possible adverse drug events after the drugs have been administered. The training program on safe administration of pediatric drugs was found to be effective in improving knowledge and practice of staff nurses in safe administration of pediatric drugs.

\section{Conflict of Interest: None \\ References}

1. Bond CA, Raehl CL, Franke T. Medication errors in United States hospitals. Pharmacotherapy 2001; 21: 1023-1036.

2. Ghaleb MA, Wong ICK. Medication errors in Children. Arch Dis Child Educ Pract Ed 2006; 91: ep20-ep-24.

3. Lesar TS. Error in the medication dosage equations. Arch pediatr Adolesc Med 1998; 152: 340-344.

4. Hughes RG, Edgerton EA. First Do No Harm, Reducing Pediatric Medication Error. AJN 2005; 105: 79-84.

5. Kaushal R, Bates DW, Landrigan $C$ et al. Medication Errors and Adverse Drug Events in Paediatric Inpatients. JAMA 2001; 285: 2114-2120.

6. Prot S, Fontan JE, Alberti C et al. Drug administration errors and their determinants in paediatric in-patients. International Journal for Quality in Health Care 2005; 17: 381-389.

7. Miller MR, Robinson KA, Lubomski LH et al. Medication errors in pediatric care. Qual Salf Health Care 2007; 16: $116-126$

8. Katie Thomas. Preventable Pediatric Medication errors. Bellaonline (document on internet). Pediatric site, 2009. Available from: http://www.bellaonline.com/ articles/.

9. Marino $\mathrm{BL}$, Reinhardt K, Eichelberger WJ et al. Prevalence of errors in a pediatric hospital medication system: implications for error proofing. Outcomes Manag Nurs Pract 2000; 4: 129-135.

10. Aneja S, Bajaj G, Mehandrita SK. Errors in medication in paediatric wards. Indian paediatrics 1992; 29: 727-730.

11. Portnoy J, Dominguez T, Lin R et al. Medication Errors in the paediatric Intensive Care Unit: Risk factors and Outcomes. Abstr Academy Health Meet 2004; 21: abstract no.1852.

12. Parihar M, Passi GR. Medical errors in pediatric practice. Indian Pediatr 2008; 45: 867-8.

13. Kopp BJ, Erstad BL, Allen ME et.al. Medication errors and adverse drug event in an intensive care unit: direct observation approach for detection. Crit Care Med 2006; 34: 415-425.

14. Lisby M, Nielsen LP, Mainz J. Errors in the medication process: frequency, type,and potential clinical consequences. Int J Qual Health Care 2005; 17: 15-22.

15. Vazin A, Delfani S. Medication errors in an internal intensive care unit of a large teaching hospital: a direct observation study. Acta Med Iran 2012; 50(6): 425-432.

16. Rinke ML, Shore AD, Morlock L et al. Characteristics of pediatric chemotherapy medication errors in a national 
error reporting database. Cancer 2008; 112: 445-6.

17. Fahimi F, Ariapanah $\mathrm{P}$, Faizi $\mathrm{M}$ et al. Errors in preparation and administration of intravenous medications in the intensive care unit of a teaching hospital: an observational study. Aust Crit Care 2008; 21(2): 110-6.

18. Tissot E, Cornette C, Limat S et al. Observational study of potential risk factors of medication administration errors. Pharm World Science 2003; 25: 264-8.

19. Van den Bemt PM, Fijn R, Van Der Voort PH et al. frequency and determinants of drug administration errors in the ICU. Crit care Med 2002; 30: 846-850.

20. Sullivan MM, O'Brien CR et al. Impact of an interactive online nursing educational module on insulin errors in hospitalized pediatric patients. Diabetes Care 2010; 33(8): 1744-6.

21. Simpson JH, Lynch R, Grant J et al. Reducing medication errors in the neonatal intensive care unit. Arch Dis Child Fetal Neonatal Ed 2004; 89(6). 